\title{
Vestibular Labyrinth Contributions to Human Whole-Body Motion Discrimination
}

\author{
Yulia Valko, ${ }^{1,3}$ Richard F. Lewis, ${ }^{1,2,3}$ Adrian J. Priesol, ${ }^{1,3}$ and Daniel M. Merfeld ${ }^{1,3}$ \\ Departments of ${ }^{1}$ Otology and Laryngology and ${ }^{2}$ Neurology, Harvard Medical School, and ${ }^{3}$ Jenks Vestibular Physiology Laboratory, Massachusetts Eye and \\ Ear Infirmary, Boston, Massachusetts 02114
}

To assess the contributions of the vestibular system to whole-body motion discrimination in the dark, we measured direction recognition thresholds as a function of frequency for yaw rotation, superior-inferior translation (" $z$-translation"), interaural translation (" $y$ translation"), and roll tilt for 14 normal subjects and for 3 patients following total bilateral vestibular ablation. The patients had significantly higher average threshold measurements than normal $(p<0.01)$ for yaw rotation (depending upon frequency, $5.4 \times$ to $15.7 \times$ greater $), z$-translation $(8.3 \times$ to $56.8 \times$ greater $), y$-translation $(1.7 \times$ to $4.5 \times$ greater $)$, and roll tilt $(1.3 \times$ to $3.0 \times$ greater $)-$ establishing the predominant contributions of the vestibular system for these motions in the dark.

\section{Introduction}

Human studies reporting whole-body motion discrimination thresholds in the dark (Clark and Stewart, 1968; Doty, 1969; Benson et al., 1989; Mah et al., 1989; Carpenter-Smith et al., 1995; De Vrijer et al., 2008; Grabherr et al., 2008; Zupan and Merfeld, 2008; Barnett-Cowan and Harris, 2009; Fetsch et al., 2009; MacNeilage et al., 2010; Mallery et al., 2010; Clemens et al., 2011; Lewis et al., 2011; Soyka et al., 2011; Roditi and Crane, 2012) often assume that the vestibular system is the predominant contributor to motion perception, but the available literature does not uniformly support this conclusion. For example, Walsh (1961) reported translation thresholds that were about 10 times greater than normal in deaf students without evidence of an angular vestibulo-ocular reflex (VOR), but Gianna et al. (1996) reported just a slight increase in the translation thresholds of vestibular defective subjects.

While other studies show that patients with various peripheral vestibular disorders generally demonstrate higher than normal nystagmic (Montandon and Russbach, 1956) and perceptual (Mann, 1951; Montandon and Russbach, 1956; Roggeveen and Nijhoff, 1956) thresholds in response to passive self-motion in the dark, no previous study has conclusively demonstrated that the vestibular periphery is the predominant sensory contributor to human motion perception under these conditions. Nor has any such patient study comprehensively assayed both canal and

Received May 4, 2012; revised July 21, 2012; accepted July 26, 2012.

Author contributions: R.F.L., A.J.P., and D.M.M. designed research; Y.V. performed research; Y.V. and D.M.M. analyzed data; Y.V., R.F.L., A.J.P., and D.M.M. wrote the paper.

This research was supported by NIH/NIDCD R01-DC04158. We appreciate the participation of all our anonymous subjects, especially our patients who travelled from out-of-town to participate. We thank Dr. Derald Brackmann and Dr. Barbara Herrmann for help finding appropriate patients for this study. We also thank Sho Chaudhuri, Wangsong Gong, Bob Grimes, Csilla Haburcakova, and Koeun Lim for assistance, and Dr. Faisal Karmali for reviewing a draft of this manuscript.

Correspondence should be addressed to Dan Merfeld, Massachusetts Eye and Ear Infirmary, 243 Charles Street, Boston, Massachusetts 02114. E-mail: dan_merfeld@meei.harvard.edu.

DOI:10.1523/JNEUROSCI.2157-12.2012

Copyright $\odot 2012$ the authors $\quad 0270-6474 / 12 / 3213537-06 \$ 15.00 / 0$ otolith thresholds_-let alone performed a comprehensive evaluation as a function of frequency.

To establish the vestibular contributions to perceptual motion thresholds, we tested three patients who had total surgical ablation of both inner ears and measured direction recognition thresholds in these patients. We did so because only the total absence of vestibular signals allows us to determine the maximal extent to which all other sensory cues (e.g., auditory, touch/pressure, somatic graviception) can substitute for absent vestibular function. To provide a broad assessment of vestibular function, we measured direction recognition thresholds for four different motions: (1) yaw rotation; (2) earth-vertical superior-inferior ("z-axis") translation; (3) earth-horizontal interaural (" $y$-axis") translation; and (4) roll tilt. Furthermore, since vestibular responses (Fernandez and Goldberg, 1971, 1976; Peterka et al., 1990; Merfeld et al., 2005), including thresholds (Benson et al., 1986, 1989; Grabherr et al., 2008; Soyka et al., 2011), vary with frequency, we measured thresholds as a function of frequency.

\section{Materials and Methods}

As for earlier human studies (Benson et al., 1986), we used a direction recognition task in which subjects report the direction of motion. Most general methods mimic those we have published (Grabherr et al., 2008). The study was approved by the local ethics committee and was performed in accordance with the ethical standards of the 1964 Declaration of Helsinki.

All subjects filled out a general health questionnaire. Normal subjects were also prescreened via clinical diagnostic testing to confirm the absence of undiagnosed vestibular disorders. Screening consisted of caloric testing, electronystagmography, Hallpike testing, angular VOR evoked via rotation, and posturography. Fourteen healthy normal volunteers ( 9 females - 5 males) participated. The mean age was $36(\sigma=10)$.

To ensure that the vestibular-deficient patients had no residual vestibular function, we studied three patients who had undergone bilateral surgical ablation of both inner ears for bilateral vestibular schwannomas associated with neurofibromatosis type 2 . We only included patients whose nerve sections were accomplished via a translabyrinthine nerve section or a transcochlear nerve section with a labyrinthectomy, because 
Table 1. Patient clinical characteristics

\begin{tabular}{|c|c|c|c|c|}
\hline Patient & $\begin{array}{l}\text { Vestibular } \\
\text { schwannoma } \\
\text { size }\end{array}$ & $\begin{array}{l}\text { Brainstem } \\
\text { compression }\end{array}$ & $\begin{array}{l}\text { Radiation or } \\
\text { chemotherapy for } \\
\text { vestibular } \\
\text { schwannoma }\end{array}$ & Other tumors \\
\hline A & $<3 \mathrm{~cm}$ & None & None & $\begin{array}{l}13 \text { Spinal (3 resected) } \\
1 \text { Femoral (resected) }\end{array}$ \\
\hline B & $\begin{array}{l}\text { Left } 2 \mathrm{~cm} \\
\text { Right unknown }\end{array}$ & Unknown & None & $\begin{array}{l}2 \text { Intracranial } \\
\text { Several spinal }\end{array}$ \\
\hline$C$ & $\begin{array}{l}\text { Left } 3 \mathrm{~cm} \\
\text { Right } 5 \mathrm{~cm}\end{array}$ & $\begin{array}{l}\text { Left none } \\
\text { Right unknown }\end{array}$ & None & $\begin{array}{l}6 \text { Intracranial (1 resected, } 1 \\
\text { treated with radiation and } \\
\text { chemotherapy), } 6 \text { spinal (1 } \\
\text { resected), } 1 \text { pelvic }\end{array}$ \\
\hline
\end{tabular}

these are the only methods that ensure complete vestibular deafferentation. All three patients were deaf and used an auditory brainstem implant during testing.

Patient A was a 24-year old female who competed in triathlons and marathons. She first had right-sided labyrinthectomy at age 9, followed by left-sided labyrinthectomy at age 19. Patient B was a 26-year old male who underwent right- and left-sided labyrinthectomies at ages 5 and 20, respectively. Although he walks with a limp, he is able to ride a bicycle. Patient $\mathrm{C}$ was a 53-year old female with a history of two right ear vestibular schwannoma removals. The first surgery was performed at age 29 using a suboccipital approach. Due to a regrowth, she needed a second removal at age 38 , this time using a translabyrinthine approach. Leftsided labyrinthectomy was performed when the patient was 47 . Additional clinical information is provided in Table 1.

Standard neurological exams showed no signs of myelopathy and no substantive sensory abnormalities other than auditory and vestibular deficits. Pressure sensation on the trunk and buttocks was tested in several locations in patients A and B using Semmes-Weinstein monofilaments (Tracey et al., 2012). Although patient A had 13 spinal tumors and patient $B$ had only several small spinal tumors, we found that their pressure thresholds on the trunk were comparable and were also comparable to those from a normal control subject. These findings suggest that the presence or absence of spinal tumors most likely did not influence peripheral sensation.

Subjects were (1) rotated in yaw, (2) translated along an earthvertical superior-inferior axis ( $z$-translation), (3) translated along an earth-horizontal interaural axis ( $y$-translation), or (4) tilted in roll about an earth-horizontal, head-centered, naso-occipital axis. Subjects always began, and except for roll tilt remained, upright with respect to gravity. Motion stimuli were generated using a MOOG 6DOF motion platform. Single cycles of sinusoidal acceleration were applied. The peak acceleration $(A)$, peak velocity $\left(\nu_{p}\right)$ and total lateral displacement $(\Delta p)$ are proportional to one another $\left(\nu_{p}=A /(\pi f)=\right.$ $2 f \Delta p$ ). These motion profiles were chosen because they mimic natural volitional head movements.

A brief low pitch "warning" tone was administered before the onset of each motion stimulus. At the end of each trial, a brief high pitch sound indicated that the subject needed to respond. Each subject was instructed to push the button in their left hand if they perceived a leftward (downward) motion or to push the button in their right hand for rightward (upward) motion. When subjects were uncertain of the motion direction, they were instructed to make their best guess.

Subjects were seated in a chair with a five-point harness in an upright position. The subject's head was held in an adjustable helmet that was carefully centered relative to the axes of rotation within $\sim 1 \mathrm{~cm}$ (Grabherr et al., 2008). To eliminate the influence of visual cues, trials were performed in the dark in a light-tight room. To minimize the influence of other sensory systems, all skin surfaces except the face were covered (long sleeves, light gloves); a clear visor was attached to the helmet surrounding the face. For normal hearing subjects, noise-cancelling earplugs reduced external noise by more than $20 \mathrm{~dB}$, and remaining auditory motion cues were masked by white noise (circa $60 \mathrm{~dB}$ ). Tactile cues were distributed as evenly as possible using padding.

Each frequency was tested in a block of trials before switching to another frequency. All four conditions were tested at $0.5,1,2$, and $5 \mathrm{~Hz}$. For yaw rotation, results are also reported for $0.2 \mathrm{~Hz}$. For $y$-translations and $z$-translations, results are also reported for $0.3 \mathrm{~Hz}$. For roll tilts, results are also reported for $0.05,0.1$, and $0.2 \mathrm{~Hz}$. Because of device displacement limitations, not all subjects were able to complete testing at all frequencies. As will be shown, patients could only complete testing at the highest frequencies for some motion conditions. For normal subjects who typically completed testing at all frequencies, testing took $10-12 \mathrm{~h}$. For total loss patients who often could not complete tests at lower frequencies, testing took 6-8 h. Testing for both normal subjects and patients was typically broken up into multiple test sessions of 30-90 min each.

Like earlier studies (Hall, 1981), we used a hybrid approach to estimate the parameters of the psychometric function. We combined an adaptive three-down/one-up staircase (Leek, 2001) that set the stimulus magnitude for each trial, with a maximum likelihood fit of the data. Direction of motion (e.g., left or right) was randomized. The maximum likelihood fit was performed using a generalized linear model (GLM) (McCullagh and Nelder, 1990; Dobson and Barnett, 2008; Zupan and Merfeld, 2008). Specifically, a Gaussian cumulative distribution function was fit to the data using a GLM with a probit link function yielding a "maximum likelihood" model fit. The data included a peak angular velocity amplitude vector $(\omega)$ and a binary motion direction response vector $(y)$. The function call in MATLAB was $b=\operatorname{glmfit}(\omega, y$, 'binomial','link','probit') using the statistics toolbox (version 7.0), where $b$ is a two-element vector. The elements of $b$ are related to an underlying Gaussian probability distribution (Dobson and Barnett, 2008), having a "vestibular bias" $(\mu)$, which represents an offset from zero (Merfeld, 2011), $\mu=-b(1) / b(2)$, and a "one-sigma threshold" $(\sigma)$, which represents the standard deviation of the noise, $\sigma=1 / b(2)$.

After each trial, the GLM fit was performed. Data collection for each subject was terminated when the coefficient of variation (CV) for the $b(2)$ fit parameter - the one representative of the one-sigma threshold for that test condition-was $<0.2$; this means that the estimated standard deviation of the spread parameter was $<20 \%$ the magnitude of the estimated spread parameter. On average, $70-80$ trials were required to yield the desired CV. Sometimes testing had to be terminated before this criterion was met. This occurred when the $3 \mathrm{D} / 1 \mathrm{U}$ staircase algorithm required large motion stimuli that exceeded the capabilities of our motion device. Prematurely terminated test sessions were repeated if time allowed. Data from two or more such test sessions were combined for analysis. Due to the probabilistic nature of thresholds, it is impossible to translate device limitations to precise measureable threshold limits, but limits would be about $30 \%$ for rotation or tilt and $30 \mathrm{~cm} / \mathrm{s}$ for translation.

As for earlier studies (Benson et al., 1986, 1989; Grabherr et al., 2008), the geometric mean across subjects was calculated because the data demonstrated a lognormal distribution across subjects. Statistical analyses were performed using a Wilcoxon rank sum test for each of the four conditions.

\section{Results}

Figure 1 shows the peak stimulus velocity at threshold as a function of frequency for each normal subject as well as the geometric mean across subjects (Table 2). Note that the ordinate and abscissa for each plot are logarithmic to accommodate the large frequency range and threshold variations. That the ordinate ( $y$ axis) is logarithmic is especially important to keep in mind, since graphical differences can sometimes be underestimated for logarithmic axes. All four datasets suggest a flat or low slope "plateau" region at higher frequencies. The yaw rotation (Fig. $1 a$ ), $z$-translation (Fig. 1b), and $y$-translation (Fig. 1d) thresholds demonstrate a substantial increase at lower frequencies, while the thresholds for roll tilt (Fig. 1c) demonstrate a substantial decrease at lower frequencies. Due to limited $z$-translation displacement, only 10 normal subjects were able to complete testing at $0.3 \mathrm{~Hz}$ 

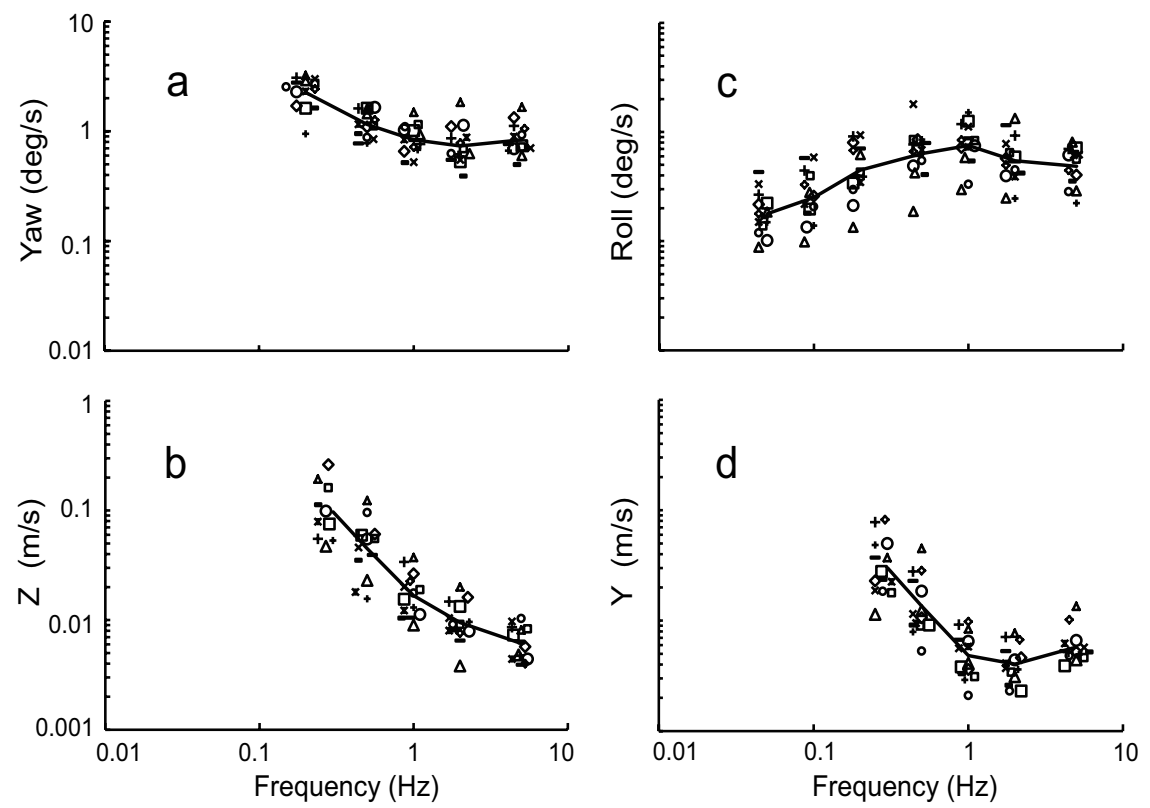

Figure 1. Thresholds for 14 normal subjects are shown as a function of frequency; the geometric mean of the data is shown due to lognormal distribution of thresholds across subjects. (a) Yaw rotation, (b) z-translation, (c) roll-tilt, and (d) y-translation thresholds are plotted. Peak velocity at threshold is shown.

Table 2. Threshold geometric mean

\begin{tabular}{lllll}
\hline Frequency $(\mathrm{Hz})$ & Yaw $(\mathrm{deg} / \mathrm{s})$ & Roll $(\mathrm{deg} / \mathrm{s})$ & $z(\mathrm{~cm} / \mathrm{s})$ & $y(\mathrm{~cm} / \mathrm{s})$ \\
\hline 0.05 & & 0.18 & & \\
0.1 & & 0.25 & & \\
0.2 & 2.26 & 0.45 & & \\
0.3 & & & $9.7^{*}$ & 3.01 \\
0.5 & 1.16 & 0.64 & $4.5^{* *}$ & 1.35 \\
1 & 0.84 & 0.75 & 1.67 & 0.48 \\
2 & 0.74 & 0.55 & 0.95 & 0.4 \\
5 & 0.84 & 0.49 & 0.61 & 0.58 \\
\hline
\end{tabular}

Thresholds are for 14 normal subjects except that a single asterisk $(*)$ indicates 10 normal subjects and two asterisks $(* *)$ indicates 13 normal subjects.

and only 13 subjects at $0.5 \mathrm{~Hz}$. For all other conditions, all 14 normal subjects were able to complete testing. Consistent with other datasets (Karmali et al., 2010), the roll tilt angle at threshold approached a constant value at low frequencies (data not shown), presumably because of the static tilt cues present after the dynamic roll tilt motion.

To allow a more straightforward comparison of these normative data to the patients, we normalize patient data by the geometric mean across the normal subjects at each frequency (Fig. 2, Table 3). The patients' yaw rotation thresholds (Fig. 2a) and $z$-translation thresholds (Fig. $2 b$ ) are strikingly greater than normal ( $p<0.01$ for each). In fact, these three patients could only complete the task at the two or three highest frequencies; for lower frequencies the motions required to assay patient thresholds were beyond device motion limits. The patient $y$-translation (Fig. $2 d$ ) and roll tilt (Fig. 2c) thresholds show a less dramatic but still significant $(p<0.01)$ increase compared to normal.

\section{Discussion}

One primary finding was that the patients suffering total bilateral vestibular loss had thresholds that were higher than normal. The average patient threshold was always at least $30 \%$ greater than the normal average for each frequency and for each motion condition. For each of the four motion conditions, the measured thresholds were significantly $(p<0.01)$ higher in the total vestibular loss patients.

A second finding was that the relative performance of the patients was much worse for yaw rotation and $z$-translation than for $y$-translation and roll tilt. In fact, patient thresholds were so high for yaw rotation and $z$-translation that testing could not be completed below $1 \mathrm{~Hz}$. In contrast, while deficits were evident, patients were able to complete testing across a broader range of frequencies for $y$-translation and roll tilt, and the disparity between normal subjects and patients was not as striking (Fig. 2).

A third finding was that for normal subjects (Fig. 1) all four motion conditions yielded what appeared to be a threshold plateau at higher frequencies. The pattern of normal thresholds as a function of frequency matches published data for yaw rotation (Grabherr et al., 2008) and $y$-translation (Soyka et al., 2011), and the values appear consistent with recently published translation (MacNeilage et al., 2010), rotation, and translation (Roditi and Crane, 2012) and tilt thresholds (Clemens et al., 2011).

Furthermore, each of the three motion conditions that included only transient motion cues (yaw rotation, $z$-translation, and $y$-translation) showed substantial threshold increases at lower frequencies. Earlier papers (Grabherr et al., 2008; Haburcakova et al., 2012) have suggested (1) that the constant velocity plateau at higher frequencies implies that the brain performs the recognition task using a velocity (as opposed to position or acceleration) signal and (2) that the increases at lower frequencies result from high-pass filtering of that velocity signal as part of the decision-making process (e.g., Aston-Jones and Cohen, 2005a,b). Depending upon motion direction, the high-pass cutoff frequency is on the order of $0.5-1 \mathrm{~Hz}$, which corresponds to time constants on the order of $0.3-0.15 \mathrm{~s}$. As noted in an earlier paper (Grabherr et al., 2008), the $0.3 \mathrm{~s}$ time constant is substantially lower than the $6 \mathrm{~s}$ peripheral time constant of the semicircular canals (Fernandez and Goldberg, 1971). We informally refer to this time constant reduction as velocity leakage, since it contrasts with the behavioral time constant increase associated with "velocity storage" (Raphan et al., 1979; Okada et al., 1999; Bertolini et al., 2011; Laurens and Angelaki, 2011; Karmali and Merfeld, 2012).

\section{Threshold variability}

Both patients and normal subjects demonstrated substantial variations across individuals. The cause of these individual variations is unknown but is consistent with earlier studies showing that thresholds varied across subjects by about a factor of 10 for both rotation (Benson et al., 1989) and translation (Benson et al., 1986).

\section{Patient thresholds across motion types}

Patient thresholds were closest to normal for roll tilt. An explanation is that the patients were able to use nonvestibular sensory cues (tactile, auditory, etc.) to a greater extent for roll tilt than for other paradigms. Following roll tilt, a static force counteracts gravity, which provides tactile cues that indicate tilt direction. In 
addition, somatic graviception (Mittelstaedt, 1996) could contribute. It seems logical that a human could effectively use such direct static nonvestibular cues to help determine roll tilt direction.

Similarly, for $y$-translation, the force acting on the body during linear acceleration indicates the direction of motion. But unlike the roll tilt condition, here only direct phasic (i.e., transient) cues are available. This static/dynamic difference may explain why the patients' thresholds were somewhat higher for $y$-translation $(1.7 \times$ to $4.5 \times$ greater $)$ than for roll tilt $(1.3 \times$ to $3.0 \times$ greater).

For $z$-translation, cue substitution is not as straightforward. As for $y$-translation, the change in nonvestibular cues indicates the direction of motion. However, since the total force acting on the body is due to both gravity and linear acceleration, the motion cue must now either add to or subtract from gravity. In other words, to use the force cue during the $z$-translation task, the brain cannot simply determine the direction of the force, which in fact is always upward, but rather, must determine whether the force increases or decreases. This is more subtle than the direct force cues available during roll tilt and $y$-translation and seems likely to explain why patient deficits were more dramatic for $z$-translation (Fig. 2b) than $y$-translation (Fig. $2 d$ ).

In comparison, other data show that normal human direction recognition thresholds do not depend on the direction of movement relative to gravity, which suggests that the vestibular nervous system normally compensates for gravity (MacNeilage et al., 2010). Such compensation is consistent with the hypothesis that the central vestibular system includes an internal neural representation of gravity (Merfeld et al., 1993; Angelaki et al., 1999; Merfeld et al., 1999; Indovina et al., 2005). More specifically, the published data (MacNeilage et al., 2010) showed that average (1) earth-vertical $z$-translation, (2) earth-horizontal $z$-translation, (3) earth-vertical $y$-translation, and (4) earth-horizontal $y$-translation thresholds were all within a factor of two. Our normal data (Fig. 1, Table 2) are consistent with this pattern, but our patient data show a strikingly different pattern. Specifically, earth-vertical $z$-translation thresholds in patients were $8-56.8$ times greater than normal when vestibular cues were eliminated via bilateral ablation. Yet, the patients' earth-horizontal $y$-translation thresholds were on average just 1.7-4.5 times greater than normal. Together with our normative data (Fig. 1) and the data presented by MacNeilage et al. (2010), these patient deficits, especially the $z$-translation deficits, suggest that compensation for nonvestibular gravitational cues is much less effective than compensation for vestibular gravitational cues. However, our study cannot rule out that patients use nonvestibular cues during $y$-axis translation more effectively than during $z$-axis translation independent of the direction of gravity.

Similar to $z$-translation, the nonvestibular cues available during yaw rotation are both indirect and transient. For yaw rotation, a torque results from forces acting on the body. In order for the pressure/force signals to provide a cue regarding rotation direction, subjects would need to somehow sum the various torques - forces $X$ radius - acting on different body parts. This cue is less direct than the force cue available during roll tilt and
Table 3. Normalized average thresholds for 3 total bilateral loss patients

\begin{tabular}{lclll}
\hline Frequency (Hz) & Yaw & Roll & $z$ & $y$ \\
\hline 0.05 & & 1.53 & & \\
0.1 & & 1.88 & & \\
0.2 & & 1.34 & & \\
0.3 & & & & 4.25 \\
0.5 & & 2.4 & & 3.61 \\
1 & $9.01^{*}$ & 2.47 & $56.78^{*}$ & 4.45 \\
2 & 15.69 & 2.03 & 11.69 & 3.06 \\
5 & 5.4 & 2.95 & 8.28 & 1.73 \\
\hline
\end{tabular}

Data are normalized by the average of the normative data (defining the normal average to equal "one ${ }^{\prime \prime}$ ). Asterisks ( ${ }^{*}$ ) show two conditions that include only one patient; thresholds for other two patients could not be assayed for these two conditions because requisite motion exceeded device limits.

$y$-translation, which probably explains the dramatic deficit observed in patient yaw rotation thresholds.

\section{Patient selection}

None of the earlier patient studies included the measurement of vestibular thresholds in more than one direction. The elevated translation thresholds we measured in patients mimicked those reported by Walsh (1961) but do not match the smaller patient threshold elevation reported by Gianna et al. (1996). While other factors (e.g., motion directions, methodologies) may play a role, we think that the difference is most parsimoniously explained by noting that Gianna and colleagues did not suggest that their patients had total vestibular loss. This would also be consistent with smaller threshold elevations reported in other earlier studies (Jongkees and Groen, 1950; Mann, 1951; Roggeveen and Nijhoff, 1956; Montandon et al., 1969) that measured thresholds in patients having a wide variety of diagnoses. While the evidence of vestibular dysfunction in the various patients was unambiguous, there was no evidence that vestibular function was totally absent in these various patients.

To state with certainly that the thresholds measured in our patients were due to contributions of other sensory systems - and 
thereby clearly establish the stimulus levels at which other sensory systems begin to provide cues relevant to our directionrecognition task - we needed to ensure that our patients had no vestibular function. Hence, patient selection was a critical factor. We only included patients with bilateral labyrinthectomies (as opposed to just nerve sections) because it provided a more conservative assurance of total vestibular loss (Brackman, 1996; Eisenman et al., 2001). It is also important to note that all patients were well compensated. Such well compensated patients probably have learned to maximize their use of all available sensory cues to make up for their vestibular deficits; normal subjects may not use nonvestibular cues to the same extent as these patients. Therefore, we interpret these patient data as likely establishing the maximum amount that nonvestibular cues can contribute to a direction-recognition task.

While thresholds for total bilateral loss patients have not previously been reported, our $y$-translation findings appear consistent with one previous study (Gu et al., 2007) that measured heading direction thresholds - a form of translation threshold in monkeys with total vestibular ablation and reported thresholds that were about 10 times greater than normal when measured 3 or more months postlesion. The Gaussian stimuli they used had a frequency component near our $1 \mathrm{~Hz}$ stimuli, where we observed average patient thresholds ranging between 3.33 and 7.23 times greater than normal.

\section{Summary}

Thresholds for patients with a complete absence of vestibular function were significantly greater than for normal subjects. This was true for all conditions but the measured patient deficit was especially prominent for yaw rotation and $z$-translation - motions that do not provide a direct nonvestibular cue to substitute for absent vestibular cues. These findings establish the dominant contribution of vestibular cues to self-motion direction recognition tasks in the dark.

\section{References}

Angelaki DE, McHenry MQ, Dickman JD, Newlands SD, Hess BJ (1999) Computation of inertial motion: Neural strategies to resolve ambiguous otolith information. J Neurosci 19:316-327. Medline

Aston-Jones G, Cohen JD (2005a) Adaptive gain and the role of the locus coeruleus-norepinephrine system in optimal performance. J Comp Neurol 493:99-110. CrossRef Medline

Aston-Jones G, Cohen JD (2005b) An integrative theory of locus coeruleusnorepinephrine function: adaptive gain and optimal performance. Annu Rev Neurosci 28:403-450. CrossRef Medline

Barnett-Cowan M, Harris LR (2009) Perceived timing of vestibular stimulation relative to touch, light and sound. Exp Brain Res 198:221-231. CrossRef Medline

Benson AJ, Spencer MB, Stott JR (1986) Thresholds for the detection of the direction of whole-body, linear movement in the horizontal plane. Aviat Space Environ Med 57:1088-1096. Medline

Benson AJ, Hutt EC, Brown SF (1989) Thresholds for the perception of whole-bodyangular movement about a vertical axis. Aviat Space Environ Med 60:205-213. Medline

Bertolini G, Ramat S, Laurens J, Bockisch CJ, Marti S, Straumann D, Palla A (2011) Velocity storage contribution to vestibular self-motion perception in healthy human subjects. J Neurophysiol 105:209-223. CrossRef Medline

Brackman D (1996) Surgical procedures: endolymphatic shunt, vestibular nerve section, and labyrinthectomy. In: Disorders of the vestibular system (Baloh R, Halmagyi GM, eds), pp 551-562. Oxford: Oxford UP.

Carpenter-Smith TR, Futamura RG, Parker DE (1995) Inertial acceleration as a measure of linear vection: an alternative to magnitude estimation. Percept Psychophys 57:35-42. CrossRef Medline

Clark B, Stewart JD (1968) Comparison of three methods to determine thresh- olds for perception of angular acceleration. Am J Psychol 81:207-216. CrossRef Medline

Clemens IA, De Vrijer M, Selen LP, Van Gisbergen JA, Medendorp WP (2011) Multisensory processing in spatial orientation: an inverse probabilistic approach. J Neurosci 31:5365-5377. CrossRef Medline

De Vrijer M, Medendorp WP, Van Gisbergen JA (2008) Shared computational mechanism for tilt compensation accounts for biased verticality percepts in motion and pattern vision. J Neurophysiol 99:915-930. CrossRef Medline

Dobson A, Barnett A (2008) An introduction to generalized linear models, Ed 3. Boca Raton, FL: Chapman and Hall/CRC.

Doty RL (1969) Effect of duration of stimulus presentation on the angular acceleration threshold. J Exp Psychol 80:317-321. CrossRef Medline

Eisenman DJ, Speers R, Telian SA (2001) Labyrinthectomy versus vestibular neurectomy: long-term physiologic and clinical outcomes. Otol Neurotol 22:539-548. CrossRef Medline

Fernandez C, Goldberg JM (1971) Physiology of peripheral neurons innervating semicircular canals of the squirrel monkey. II. Response to sinusoidal stimulation and dynamics of peripheral vestibular system. J Neurophysiol 34:661-675. Medline

Fernández C, Goldberg JM (1976) Physiology of peripheral neurons innervating the otolith organs of the squirrel monkey. III. Response dynamics. J Neurophysiol 39:996-1008. Medline

Fetsch CR, Turner AH, DeAngelis GC, Angelaki DE (2009) Dynamic reweighting of visual and vestibular cues during self-motion perception. J Neurosci 29:15601-15612. CrossRef Medline

Gianna C, Heimbrand S, Gresty M (1996) Thresholds for detection of motion direction during passive lateral whole-body acceleration in normal subjects and patients with bilateral loss of labyrinthine function. Brain Res Bull 40:443-449. CrossRef Medline

Grabherr L, Nicoucar K, Mast FW, Merfeld DM (2008) Vestibular thresholds for yaw rotation about an earth-vertical axis as a function of frequency. Exp Brain Res 186:677-681.

Gu Y, DeAngelis GC, Angelaki DE (2007) A functional link between area MSTd and heading perception based on vestibular signals. Nat Neurosci 10:1038-1047. CrossRef Medline

Haburcakova C, Lewis RF, Merfeld DM (2012) Frequency dependence of vestibuloocular reflex thresholds. J Neurophysiol 107:973-983. CrossRef Medline

Hall JL (1981) Hybrid adaptive procedure for estimation of psychometric functions. J Acoust Soc Am 69:1763-1769. CrossRef Medline

Indovina I, Maffei V, Bosco G, Zago M, Macaluso E, Lacquaniti F (2005) Representation of visual gravitational motion in the human vestibular cortex. Science 308:416-419. CrossRef Medline

Jongkees LB, Groen J (1950) A quantitative analysis of the reactions of a person after loss of function of both inner ears. J Laryngol Otol 64:135-140. CrossRef

Karmali F, Merfeld DM (2012) A distributed, dynamic, parallel computational model: the role of noise in velocity storage. J Neurophysiol 108 : 390-405. CrossRef Medline

Karmali F, Nicoucar K, Lim K, Merfeld DM (2010) Visual-vestibular fusion in sensory recognition thresholds for roll tilt direction. Soc Neurosci Abstr 36:677.7.

Laurens J, Angelaki DE (2011) The functional significance of velocity storage and its dependence on gravity. Exp Brain Res 210:407-422. CrossRef Medline

Leek MR (2001) Adaptive procedures in psychophysical research. Perception and psychophysics 63:1279-1292. CrossRef Medline

Lewis RF, Priesol AJ, Nicoucar K, Lim K, Merfeld DM (2011) Abnormal motion perception in vestibular migraine. Laryngoscope 121:1124-1125. CrossRef Medline

MacNeilage PR, Banks MS, DeAngelis GC, Angelaki DE (2010) Vestibular heading discrimination and sensitivity to linear acceleration in head and world coordinates. J Neurosci 30:9084-9094. CrossRef Medline

Mah RW, Young LR, Steele CR, Schubert ED (1989) Threshold perception of whole-body motion to linear sinusoidal stimulation. Paper presented at AIAA-89-3273, American Institute of Aeronautics and Astronautics Flight Simulation Technologies Conference and Exhibit. Boston, MA, August.

Mallery RM, Olomu OU, Uchanski RM, Militchin VA, Hullar TE (2010) Human discrimination of rotational velocities. Exp Brain Res 204:11-20. CrossRef Medline 
Mann CW (1951) The effects of auditory-vestibular nerve pathology on space perception. J Exp Psychol 42:450-456. CrossRef Medline

McCullagh P, Nelder J (1990) Generalized linear models, Ed 2. Boca Raton, FL: Chapman and Hall.

Merfeld DM (2011) Signal detection theory and vestibular thresholds: I. Basic theory and practical considerations. Exp Brain Res 210:389-405. CrossRef Medline

Merfeld DM, Young LR, Oman CM, Shelhamer MJ (1993) A multi- dimensional model of the effect of gravity on the spatial orientation of the monkey. J Vestib Res 3:141-161. Medline

Merfeld DM, Zupan L, Peterka RJ (1999) Humans use internal models to estimate gravity and linear acceleration. Nature 398:615-618. CrossRef Medline

Merfeld DM, Park S, Gianna-Poulin C, Black FO, Wood S (2005) Vestibular perception and action employ qualitatively different mechanisms. I. Frequency response of VOR and perceptual responses during translation and tilt. J Neurophysiol 94:186-198. CrossRef Medline

Mittelstaedt H (1996) Somatic graviception. Biol Psychol 42:53-74. CrossRef Medline

Montandon A, Russbach A (1956) The liminal rotation test in vestibular syndrome. Acta Otolaryngol 46:264-276. CrossRef Medline

Montandon A, Huguenin S, Rohr A, Luyet M, Pitteloud M (1969) The nystagmus threshold: basis of vestibulometry. Acta Otolaryngol 67:293-302. CrossRef Medline

Okada T, Grunfeld E, Shallo-Hoffmann J, Bronstein AM (1999) Vestibular perception of angular velocity in normal subjects and in patients with congenital nystagmus. Brain 122:1293-1303. CrossRef Medline

Peterka RJ, Black FO, Schoenhoff MB (1990) Age-related changes in human vestibulo-ocular reflexes: sinusoidal rotation and caloric tests. J Vestib Res 1:49-59. Medline

Raphan T, Matsuo V, Cohen B (1979) Velocity storage in the vestibuloocular reflex arc (VOR). Exp Brain Res 35:229-248. Medline

Roditi RE, Crane BT (2012) Directional asymmetries and age effects in human self-motion perception. J Assoc Res Otolaryngol 13:381-401. CrossRef Medline

Roggeveen LJ, Nijhoff P (1956) The normal and pathological threshold of the perception of angular accelerations for the optogyral illusion and the turning sensation. Acta Otolaryngol 46:533-541. CrossRef Medline

Soyka F, Robuffo Giordano P, Beykirch K, Bülthoff HH (2011) Predicting direction detection thresholds for arbitrary translational acceleration profiles in the horizontal plane. Exp Brain Res 209:95-107. CrossRef Medline

Tracey EH, Greene AJ, Doty RL (2012) Optimizing reliability and sensitivity of Semmes-Weinstein monofilaments for establishing point tactile thresholds. Physiol Behav 105:982-986. CrossRef Medline

Walsh EG (1961) Role of the vestibular apparatus in the perception of motion on a parallel swing. J Physiol 155:506-513. Medline

Zupan LH, Merfeld DM (2008) Interaural self-motion linear velocity thresholds are shifted by roll vection. Exp Brain Res 191:505-511. CrossRef Medline 